\title{
Infra Mammary Approach for Major Duct Excision in the Management of Multiple Duct Ectasia: Our First Steps
}

\section{Ayman Aly Reda, Tamer M Said* and Sherif Mourad}

Department of General Surgery, Ain Shams university, Egypt

\begin{abstract}
Objective: Worldwide, classical Hadfield's operation is recognized as the main surgical procedure for MDE. However, this operation can suffer from certain complications such as the loss of nipple sensation and in some cases skin necrosis and skin loss may take place. This study is aiming to evaluate this new technique (infra mammary approach) for major duct excision as regard operative time and postoperative outcome with especial concern to postoperative complications.
\end{abstract}

Patients and method: Inframammary major duct excision was performed on forty five non-lactating female patients suffering from nipple discharge that was either unilateral or bilateral.

Results: The postoperative hospital stay was one day. Suction drain was removed after 4 to 10 days of surgery (mean time 6 days). No seroma or hematomas were observed after removal of the drain. Stitches were removed after 10 to 12 days of surgery after complete healing of the wound. Nipple vitality and sensation were intact in all patients and no color change was recorded. No recurrent discharge was noticed during follow up visits. $95 \%$ of patients were satisfied by the result of surgery.

Conclusion: Although this was a pilot study that should have been supported by larger number of cases as well as by a comparative study, we can still show that the inframammary approach is superior to the classical approach for major duct excision since it can achieve duct excision while preserving the sensory nerve supply as well as the blood supply of the nipple and areola complex with the normal projection of the nipple and is therefore associated with a higher patients satisfaction.

Keywords: Management of duct ectezia; Complication of major duct excision

\section{Introduction}

In some cases, non-lactating women can experience nipple discharge that can be highly distressing. Such discharge is commonly caused by mammary ductal ectasia (MDE) [1].

Factors that can lead to mammary duct ectasia are still undefined. However, possible causes of MDE can include congenital abnormalities of the ductal system, autoimmune reactions, trauma or infections [2-4].

The pathogenesis of duct ectasia includes the dilatation of one or more of the large lactiferous ducts that are filled with a stagnant secretion. These fluids trigger an irritation reaction in the surrounding tissues causing periductal mastitis or abscess and fistula formation [5]. In some instances, a chronic indurated mass formation can take place underneath the areola that may resemble a carcinoma. This can consequently leads to fibrosis and may cause slit-like nipple retraction. In those cases, carcinoma must be excluded by performing a mammogram and cytology or histology investigations $[6,7]$. Some other explanation suggests that periductal inflammation is the primary cause [1].

MDE treatment may be approached with antibiotic therapy. However in advanced cases surgical intervention is recognized as the best treatment option [8].

Worldwide, classical Hadfield's operation is recognized as the main surgical procedure for MDE. However, this operation can suffer from certain complications such as the loss of nipple sensation and in some cases skin necrosis and skin loss may take place as a result of nerve cutting and decreased blood supply of the nipple and areola complex [9].

This study is aiming to evaluate this new technique (infra mammary approach) for major duct excision as regard operative time and postoperative outcome with especial concern to postoperative complications.

\section{Patients and Methods}

This study was performed on forty five non-lactating female patients suffering from nipple discharge that was either unilateral or bilateral with a mean age of 37 years ranging from 31 to 50 years. The study was performed in a two years period between January 2014 and January 2016. All patients were operated in the breast unit at Ain Shams University Hospital in Cairo, Egypt. Approval from the ethical committee of the Faculty of Medicine at Ain Shams University was obtained and an informed written consent was received from all patients to be enrolled in our study.

Our patients' criteria included: the existence of unilateral or bilateral duct ectasia, an age range from 26 to 50 years old and the presence of pre-established families with no desire of additional children. Patients were excluded from the study if any of the following criteria were found: positive cytology for malignancy, bleeding per nipple (proved by benzidine test), the presence of breast lump, pregnancy, having the desire for future lactation, the presence of milk discharge or showing a fair response to medical treatment.

Patients were assessed prior to surgery by taking detailed medical history and performing thorough clinical examinations. Apart from the routine preoperative investigations, all patients were investigated by

${ }^{*}$ Corresponding author: Dr. Tamer M Said, Faculty of Medicine, Department of Surgery, Ain Shams University, 16 Foud Badwany Street Nasr City, Cairo, Egypt, Tel: 01113623458; E-mail: drtamer1981@hotmail.com

Received June 26, 2016; Accepted July 14, 2016; Published July 20, 2016

Citation: Reda AA, Said TM, Mourad S (2016) Infra Mammary Approach for Major Duct Excision in the Management of Multiple Duct Ectasia: Our First Steps. Surgery Curr Res 6: 273. doi:10.4172/2161-1076.1000273

Copyright: $\odot 2016$ Reda AA, et al. This is an open-access article distributed under the terms of the Creative Commons Attribution License, which permits unrestricted use, distribution, and reproduction in any medium, provided the original author and source are credited. 
Citation: Reda AA, Said TM, Mourad S (2016) Infra Mammary Approach for Major Duct Excision in the Management of Multiple Duct Ectasia: Our First Steps. Surgery Curr Res 6: 273. doi:10.4172/2161-1076.1000273

Page 2 of 4

bilateral mammogram and breast ultrasound (for the detection of any lumps), benzidine test, cytology examination, culture and sensitivity for the discharge.

Before anesthesia, the inframammary fold was labeled while the patient was in a standing position. The operation was performed under general anesthesia and prophylactic antibiotic treatment $(100 \mathrm{ml}$ metronidazol and 1,2 gm amoxicillin and clavulonic acid ) was given to all patients.

Patients were placed in the supine position with both arms fully abducted. The whole breast was sterilized with povidine iodine and the incision was mad in the inframammry fold (Figure 1).

Breasts' skin was pulled upward and main breast tissue was compressed downward and diathermy sharp dissection was done through the breast tissue until reaching the border of the areola (Figure 2).

The ducts coming from the nipple were then dissected out of the areola and nipple by a scissor with the help of traction and counter traction between the breast skin and the duct system (Figure 3). By this technique, all the ducts were separated completely and carefully from the base of the nipple and areola (Figure 4).

Then we inverted the nipple and if duct remnants were detected, they were shaved by scalpel trying avoiding injury to skin. Burs string suture around the base of the nipple was done to evert it.

Then the cone containing all the duct system was dissected down to the sheath using diathermy until pectoral fascia was reached which represented the end point of the excised cone.

Finally, we inserted vacuum suction drain in the breast tissue followed by proper hemostasis, closure of inframammary incision by subcutaneous stitches (Figure 5) and closure of the skin by subcuticular stitches.

Oral intake was only allowed after three hours following the surgery. Treatment was removed after delivering less than $20 \mathrm{cc}$ serous fluid.

Patients were discharged one day after the operation. The excised specimen sent for histopathology. Patient visits outpatient clinic two days after surgery then once every week for one year. Postoperative scar, nipple sensation and vascularity, skin complication and over all patient satisfaction were recorded at every visit.

\section{Results}

This study was performed on 45 female patients suffering from either uni- or bilateral nipple discharge with a mean age of 37 that ranged between 31 to 50 years. The intraoperative time ranged from 35 to 65 minutes with a mean operative time of 50 minutes. No intraoperative complications occurred and none of the patients needed blood transfusion.

The postoperative hospital stay was one day. Suction drain was removed after 4 to 10 days of surgery (mean time 6 days) when it delivered less than $20 \mathrm{cc}$ serous fluid. No seroma or hematomas were observed after removal of the drain. Stitches were removed after 10 to 12 days of surgery after complete healing of the wound (Table 1).

During the follow up visits, three cases were suffering from superficial wound infection that responded well to antibiotic treatment and daily dressing, while the rest of the wounds were healed by primary intention. Nipple vitality and sensation were intact in all patients and no color change was recorded. No recurrent discharge was noticed during follow up visits. No mortality related to the operation was recorded and all patients were satisfied by the result of surgery.

\section{Discussion}

Periductal mastitis and duct ectasia are benign breast conditions that are commonly associated with multiduct nipple discharge [10] Persistent multiduct nipple discharge especially when associated with periareolar sepsis or when seriously interferes with patients' quality of life requires surgical treatment in which total duct excision or Hadfield's operation are the classic treatment options [11].

The classical Hadfield's operation is characterized by an incision made at the areolar border and the nipple where the areola skin flap is raised and the entire subareolar duct complex is excised immediately beneath the nipple dermis to a depth of 4 to $5 \mathrm{~cm}$ within breast tissue [12]. This operation however, is associated with nipple anesthesia in most patients (one in every 3 female patients) and nipple/areola necrosis in some patients and in certain cases, recurrent sepsis may take place $[9,13]$.

Studying the pattern of blood and nerve supply of the nipple and areola complex helped in understanding the reasons behind anesthesia and necrosis of the nipple and areola complex that are often associated with classic Hadfield's operation. In 1995, Nakajima et al [14] radiographically investigated the blood supply of the nipple-areola

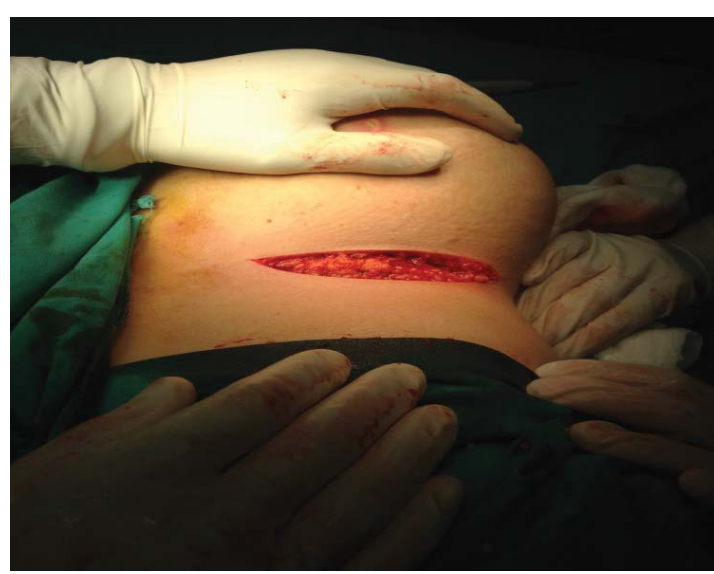

Figure 1: Inframammary incision.

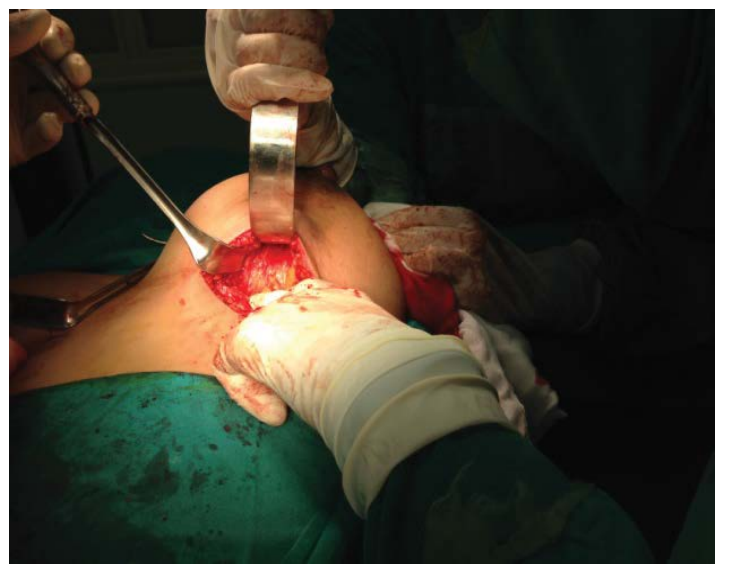

Figure 2: Dissection was done through the breast tissue until reaching the border of the areola. 
Citation: Reda AA, Said TM, Mourad S (2016) Infra Mammary Approach for Major Duct Excision in the Management of Multiple Duct Ectasia: Our First Steps. Surgery Curr Res 6: 273. doi:10.4172/2161-1076.1000273

Page 3 of 4

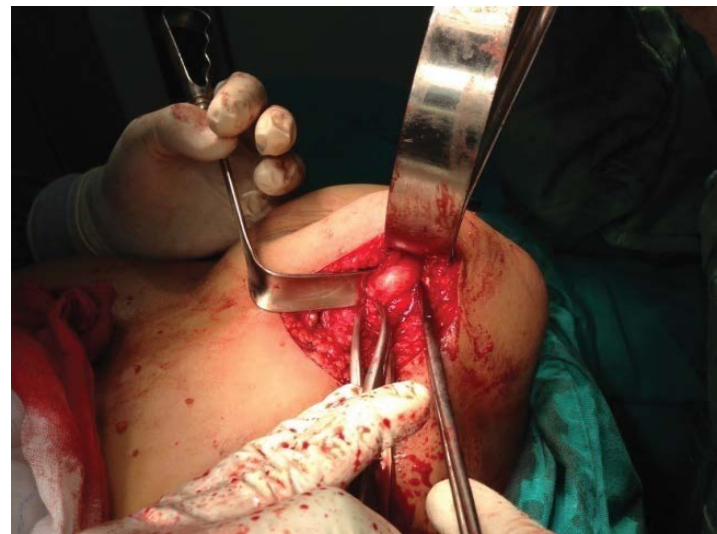

Figure 3: The ducts coming from the nipple were dissected out of the areola and nipple.

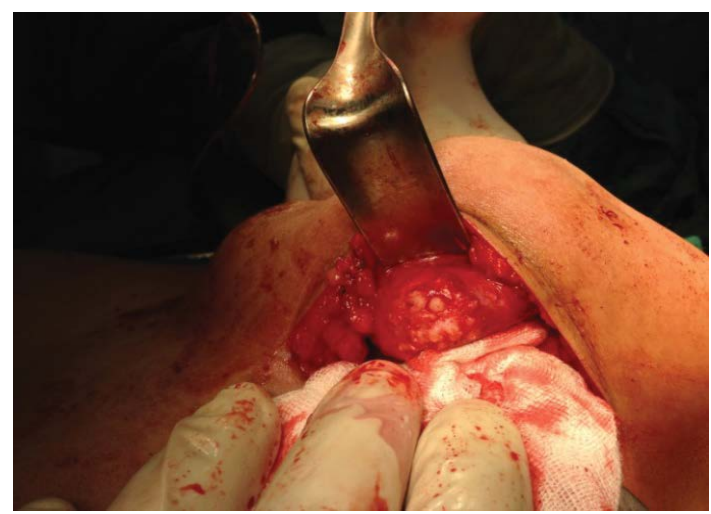

Figure 4: Ducts were separated completely and carefully from the base of the nipple and areola.

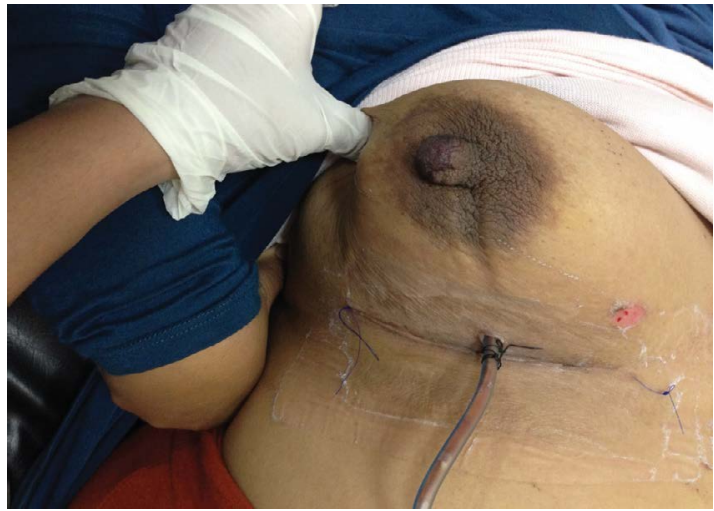

Figure 5: Final shape of the breast after the operation.

\begin{tabular}{|l|l|l|l|l|}
\hline & Mean & $\mathbf{\pm S D}$ & Min & Max \\
\hline Age & 37.6 & 5.3 & 31 & 50 \\
\hline Operative time(min) & 50.1 & 19.1 & 35 & 65 \\
\hline $\begin{array}{l}\text { Duration of suction drain } \\
\text { insertion(days) }\end{array}$ & 6.2 & 3.2 & 4 & 10 \\
\hline Duration of stitches(days) & 9.5 & 0.6 & 10 & 12 \\
\hline Post operative stay(days) & 1.1 & 0.6 & 1 & 2 \\
\hline
\end{tabular}

Table 1: Age, Operative time, Duration of suction drain insertion, Duration of stitches and postoperative hospital stay. complex in five fresh cadavers that had been systemically injected with lead oxide. They have showed that branches of the external and internal mammary arteries predominantly provide blood supply to the nippleareola complex. In addition, these branches provide small vessels that traverse the subcutaneous tissue to the nipple-areola complex which are mainly located in the upper and middle thirds of the nipple.

In another study [15] that was conducted in 1996 on 12 breast female cadavers to meticulously study the breasts' nerve supply, they found that the breasts receive its innervation from the lateral and anterior cutaneous branches of the second to the sixth intercostal nerves and from the supraclavicular nerves. Those nerves were traced to a plexus under the areola. The nerves to the nipple are located in the superficial fascia and passed through the subdermal tissue of the areola to form a plexus underneath it.

In contrast to Hadfield operation, patients who underwent our technique did not suffer from postoperative nipple or areola loss of sensation or necrosis which can be attributed to the use of inframammary incision instead of per areolar incision and avoiding raising areolar skin flap. Therefore, cutting of the subdermal nerve plexus and subcutaneous blood vessels that supply the nipple areola complex was avoided.

This approach enabled us to dissect the whole duct system completely with complete vision from underneath the nipple down to the pectoral fascia and allowed us to completely remove all ducts without leaving any remnants and therefore decreased the risk of any residual infection. This also could possibly explain the absence of recurrent cases in our study.

In our study, the overall patients' satisfaction was around $95 \%$ since the main pathology was treated with optimum breast shape including nipple projection and hidden scar with negligible postoperative complication.

\section{Conclusion}

Although this was a pilot study that should have been supported by larger number of cases as well as by a comparative study, we can still show that the inframammary approach is superior to the classical approach for major duct excision since it can achieve duct excision while preserving the sensory nerve supply as well as the blood supply of the nipple and areola complex with the normal projection of the nipple and is therefore associated with a higher patients satisfaction.

\section{References}

1. Thomas WG, Williamson RC, Davies JD, Webb AJ (1982) The clinical syndrome of mammary duct ectasia. Br J Surg 69: 423-425.

2. Böber $E$, Ozer $E$, Akgür $F$, Büyükgebiz $A$ (1996) Bilateral breast masses and bloody nipple discharge in a two-year-old boy. J Pediatr Endocrinol Metab 9 : 419-421.

3. Stringel G, Perelman A, Jimenez C (1986) Infantile mammary duct ectasia: a cause of bloody nipple discharge. J Pediatr Surg 21: 671-674.

4. Peters F, Schuth $W(1989)$ Hyperprolactinemia and nonpuerperal mastitis (Duct Ectasia) JAMA. 261: 1618-1620.

5. Haagensen CD (1951) Mammary-duct ectasia; a disease that may simulate carcinoma. Cancer 4: 749-761.

6. Dogan BE, Ceyhan K, Tukel S, Saylisoy S, Whitman GJ (2005) Ductal dilatation as the manifesting sign of invasive ductal carcinoma. J Ultrasound Med 24 $1413-1417$.

7. Duchesne N, Skolnik S, Bilmer S (2005) Ultrasound appearance of chronic mammary duct ectasia. Can Assoc Radiol J 56: 297-300.

8. Izzidien AY (1982) Mammary duct ectasia. J R Coll Surg Edin 27: 361-362. 
Citation: Reda AA, Said TM, Mourad S (2016) Infra Mammary Approach for Major Duct Excision in the Management of Multiple Duct Ectasia: Our First Steps. Surgery Curr Res 6: 273. doi:10.4172/2161-1076.1000273

9. Chapman D, Bennett-Britton T, Purushotham A, Wishart G (2006) Postoperative complications following subareolar duct clearance. Cancer Nursing Practice 5: 36-39.

10. Dixon JM, Ravisekar O, Chetty U, Anderson TJ (1996) Periductal mastitis and duct ectasia: different conditions with different aetiologies. Br J Surg 83: 820822.

11. Lanitis S, Filippakis G, Thomas J, Christofides T, Al Mufti R, et al. (2008) Microdochectomy for singleduct pathologic nipple discharge and normal or benign imaging and cytology. Breast 17: 309-313.
12. Harris JR, Hellman S, Henderson IC (1987) In: Morrow M (ed). Management of common breast disorders. Breast Diseases. (2ndedn). JB Lippincott Co,Philadelphia.

13. Srivastava A, Griwan MS, Samaiyar SS, Sharma LK (1995) A safe technique of major mammary duct excision. J R Coll Surg Edinb 40: 35-37.

14. Nakajima H, Imanishi N, Aiso S (1995) Arterial anatomy of the nipple-areola complex. Plast Reconstr Surg 96: 843-845.

15. Sarhadi NS, Shaw Dunn J, Lee FD, Soutar DS (1996) An anatomical study of the nerve supply of the breast, including the nipple and areola. Br J Plast Surg 49: $156-164$ 